Revista Multidisciplinar do Nordeste Mineiro, v.2 2019/02

ISSN 2178-6925

\title{
A CRIANÇA COM TRANSTORNO DO ESPECTRO AUTISTA NA EDUCAÇÃO INFANTIL: MEDIAÇÂO DO PROFESSOR PARA FAVORECER O POTÊNCIAL COGNITIVO
}

\author{
Andréa Ferreira Dos Santos \\ Acadêmica do $7^{\circ}$ Período do curso de Pedagogia da Faculdade Presidente Antônio Carlos \\ de Teófilo Otoni. E-mail: (andreaferreira_santos@hotmail.com)
}

Rosenéri Lago de Sousa Araújo Professor (a) da Faculdade Presidente Antônio Carlos de Teófilo Otoni, Mestre em Educação, com especialização em Neurociência da aprendizagem; Docência do Ensino Superior, Química. Graduada em Licenciatura das Ciências da Natureza, Matemática e Química. E-mail: (nerinhalago@gmail.com)

Marilda de Souza Lima

Professora e Coordenadora do curso de Pedagogia da Faculdade Presidente Antônio Carlos de Teófilo Otoni. E-mail: (marilda_souza2011@hotmail.com)

\section{Resumo}

A Lei no 12.764, de 27 de dezembro/2012, nomeada Lei Berenice Piana, assegura os direitos da pessoa com transtorno do espectro autista e no seu art. $4^{\circ}$ institui o direito à escolaridade em um sistema educacional inclusivo. Reconhecendo a legalidade e a importância da formação da criança com transtorno do espectro autista (TEA), ainda na educação infantil, cabe a preocupação de pesquisar como o professor pode mediar o ensino-aprendizagem para favorecer o potencial cognitivo dessa criança na educação infantil. Para isso é necessário que um bom professor mediador busque intervenções de maneira significativa para desenvolver a cada etapa o potencial cognitivo do aluno com TEA. O autismo é um transtorno de neurodesenvolvimento com variações em gravidade (leves a graves) e são denominados transtornos do espectro do autismo ou transtorno do espectro autista (TEA), apresentando características diferenciadas no quadro comportamental envolvendo também as áreas da interação social e da comunicação. Esse artigo tem objetiva analisar estratégias de mediação do professor para favorecer o potencial cognitivo com TEA. A metodologia utilizada quanto à abordagem é qualitativa. Quanto aos meios foi uma revisão literária no sentido de buscar em diversas produções científicas alternativas educativas que venham a atender as crianças com TEA, tanto no aspecto cognitivo, afetivo, quanto na interação com os colegas.

Palavras-chave: Transtorno do Espectro Autista. Educação Infantil. Potencial Cognitivo. Mediação do professor.

\begin{abstract}
Law №. 12,764, of December 27, 2012, which receives the name of Law Berenice Piana, assures the rights of the person with autistic spectrum disorder and its art. 4th establishes the right to schooling in an inclusive education system. Recognizing the
\end{abstract}


legality and importance of the formation of children with autism spectrum disorder (ASD), even in early childhood education, it is important to investigate how the teacher can mediate teaching and learning to favor the cognitive potential of this child in early childhood education. This requires that a good mediator teacher seeks interventions in a meaningful way to develop at each stage the cognitive potential of the student with ASD. Autism is known to be a neurodevelopmental disorder with variations in severity (mild to severe) and are called autism spectrum disorders or autistic spectrum disorder (ASD), presenting different characteristics in the behavioral picture also involving the areas of social interaction. and communication. The present article aims to analyze teacher mediation strategies to favor the cognitive potential of the autistic spectrum child. The methodology used for the approach is qualitative. As for the means, it was a literary review in order to seek in various scientific productions educational alternatives that will assist children with ASD, both in the cognitive, affective aspect and in interaction with peers.

Keywords: Autistic Spectrum Disorder. Child education. Cognitive potential. Mediation of the teacher.

\section{Introdução}

O Transtorno do Espectro Autista (TEA) possui um conjunto de diferentes síndromes que são caracterizadas por perturbações do seu desenvolvimento neurológico, que é marcado pelo desafio de interação e comunicação social por conta da fala e comunicação não verbal que se encontra dificuldades, padrões estereotipados e repetitivos de comportamento e desenvolvimento intelectual irregular, frequentemente com retardo mental.

A educação infantil engloba a primeira etapa do processo de educação, tendo como finalidade o atendimento integral da criança, sendo assim a escola tem que estar preparada para receber diversos alunos independentes das diferenças que possam apresentar. A Lei Berenice Piana, n 12.764, que foi sancionada em 27 de dezembro de 2012, assegura os direitos da pessoa com transtorno do espectro autista, representando um marco histórico na luta pelos direitos dos autistas, que faz com que haja a inclusão do o acesso a direitos previstos na legislação, tendo benefícios financeiros, garantia à educação em escolas regulares e de ingresso no mercado de trabalho, entre outros.

O aluno com TEA por possuir déficits de comunicação e interação social, e muitas vezes alguns comportamentos inadequados, faz com que seja necessária a presença do professor do atendimento Educacional Especial (AEE), que vai orientar e auxiliar os de mais com elaboração e planejamentos, para que possam ser trabalhados de acordo com a necessidade de cada aluno com o transtorno. 
O educador se vê a frente de desafios para desempenhar um trabalho que tenha um resultado satisfatório em relação ao ensino-aprendizagem quando se refere ao potencial cognitivo do aluno com TEA na educação infantil. Sendo assim justifica-se esse trabalho pela importância da formação da criança com TEA na educação infantil, pois é necessário que o professor mediador busque intervenções que ajuda no desenvolvimento do potencial cognitivo do aluno com TEA.

O objetivo deste estudo foi analisar estratégias de mediação do professor para favorecer o potencial cognitivo da criança autista na educação infantil.

Atendendo o objetivo, fez-se a pergunta problema: Como deve ser a mediação do professor para favorecer o potencial cognitivo da criança com TEA na educação infantil?

O desenvolvimento da pesquisa ocorreu mediantes estudos sobre a criança com transtorno do espectro autista na educação infantil: mediação do professor para favorecer o potencial cognitivo, trabalhando assim em tópico como: Transtorno do espectro do autismo (TEA): Alguns aspectos; A Inclusão de crianças com TEA no ensino regular, em especial na educação infantil; Mediação do professor na inclusão de alunos com Transtorno do Espectro Autista.

Este estudo trata de uma revisão bibliográfica de natureza qualitativa e explicativa. Foram utilizadas as bases de dados virtuais como SCIELO (Scientific Electronic Library Online), LILACS (Literatura Latino Americana e do Caribe em Ciências da Saúde), Google Acadêmico. Além destas, também foi realizada consulta em livros no acervo da UNIPAC (Universidade Presidente Antônio Carlos) de busca pelas obras nas bases de dados que se processou com a utilização dos seguintes descritores (palavras-chave): Transtorno do Espectro Autista. Educação Infantil. Potencial Cognitivo. Mediação do professor.

\section{Transtorno do espectro do autismo (TEA): Alguns aspectos}

Segundo Bossa (2006), o TEA é classificado atualmente como um transtorno invasivo do desenvolvimento que engloba graves dificuldades no decorrer da vida, causando déficits persistentes na comunicação e interação social em vários contextos, de comportamentos e interesses limitados e repetitivos.

O TEA é condição observada precocemente e suas dificuldades afetam 0 desenvolvimento global do indivíduo, no decorrer da sua vida, fazendo com que haja 
uma grande inconstância na intensidade e forma de expressão dos sintomas, nas áreas que definem o seu diagnóstico.

Souza (2015) afirma que os sinais do TEA começam a serem notados antes do três anos de idade, os pais percebem o déficit de resposta dos estímulos, em alguns casos os bebes não procuram pela mãe e não reagem a atitudes de carinho. O diagnóstico do TEA é feito por uma equipe multidisciplinar observando a criança em diversas situações, e após o diagnostico a família busca tratamentos específicos para orientar a criança, em busca de uma melhor qualidade de vida, para que tenha condições de desenvolver seus aspectos sensoriais, sociais e motores.

Existem vários aspectos que podem dificultar o início da busca do profissional para a realização do diagnostico para dar início a intervenção do tratamento adequado, entre esses aspectos estão as dificuldades de detectar os primeiro déficits do comportamento da criança. Alguns estudos mostram que dificilmente as crianças com TEA recebem o diagnóstico antes dos cinco anos (ZANON, 2014).

O desenvolvimento pode variar de acordo com o grau do déficit cognitivo, os que possuem o seu déficit mais grave têm menos possibilidade de desenvolver a linguagem e tem uma maior chance de apresentar comportamentos auto-agressivos. A dificuldade para socializar e comunicar permanecem durante toda a vida, porém pode haver uma melhora da qualidade de vida bem com o passar dos anos, quando recebem cuidados adequados (BOSA, 2006).

O fenótipo dos pacientes com TEA são sintomas notáveis que podem variar, sendo indivíduos com deficiência intelectual (DI) baixa ou grave desenvolvimento de habilidades comportamentais, ou até mesmo indivíduos com quociente de inteligência (QI) normal, que têm uma vida independente. (OLIVEIRA, 2017).

\section{A Inclusão de crianças com TEA no ensino regular, em especial na educação infantil}

A legislação brasileira seguiu a tendência mundial de proteção e inclusão das pessoas com demandas especiais, nelas inseridas os autistas e seus transtornos.

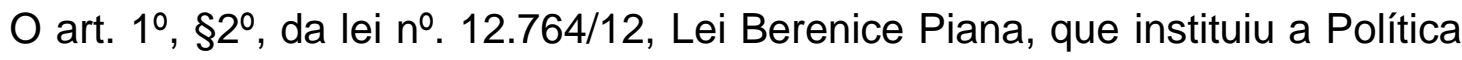
Nacional de Proteção dos Direitos da Pessoa com Transtorno do Espectro Autista, deixa claro que o indivíduo diagnosticado no espectro autista é considerado pessoa com deficiência, para todos os efeitos legais. 
Já a Lei №. 9394/96, Lei de Diretrizes e Bases da Educação Nacional, no seu art. 59, dispõe que todas as escolas devem assegurar aos estudantes um atendimento adequado às suas necessidades.

\footnotetext{
Art. 59. Os sistemas de ensino assegurarão aos educandos com deficiência, transtornos globais do desenvolvimento e altas habilidades ou superdotação:

I - currículos, métodos, técnicas, recursos educativos e organização específicos, para atender às suas necessidades;

(...)

III - professores com especialização adequada em nível médio ou superior, para atendimento especializado, bem como professores do ensino regular capacitados para a integração desses educandos nas classes comuns;
}

Constituição/1988 determina a educação como direito de todos e a Lei de Diretrizes e Bases da Educação, no art. 29 e art. 30 inciso II da Educação Infantil, define que esta seja oferecida em pré-escolas para todas as crianças de 4 a 5 anos de idade. Dessa forma, a escola de Educação Infantil necessita estar preparada para receber alunos independentemente de sua diferença, uma vez que o processo de inclusão ou exclusão escolar inicia-se ali, e, com afirma Montoan (2003), para que a escola possa ser considerada inclusiva de fato, é preciso que receba e acolha os alunos independente de suas condições de qualquer ordem, tendo como objetivo básico desenvolver uma pedagogia capaz de educar e incluir todos aqueles que apresentem dificuldades, sejam elas educacionais, temporárias ou permanentes.

Para que a escola seja realmente inclusiva, esta precisa rever seus métodos e práticas de ensino e de avaliação tomando por base as habilidades e interesses dos alunos, avaliação contínua, compreensão dos significados, colaboração dos pais, as relações de causa e efeito, a comunicação e independência, trabalhados por meio de informações visuais, rotinas e previsibilidade em ambientes naturais e com diversidade de materiais e um currículo funcional natural que visa desenvolver habilidades para essas crianças atuarem da melhor forma possível, tornando-os independentes e criativos, além de serem vistos como pessoas comuns e todos a sua volta devem agir com naturalidade, enfatizando as habilidades, as ordens devem ser claras, sem repetição e com tempo suficiente para a resposta do aluno, sempre com muita calma e estimulando a interagirem como colega. Os elogios devem ser descritivos, as ajudas físicas evitadas de forma a oportunizar as tentativas e esforços do aluno e todo interesse deve ser visto como uma oportunidade para o ensino de novas habilidades. Nesse contexto todo, é importante 
a participação dos pais, auxiliando e reafirmando o trabalho desenvolvido na escola (BOETTGER; LOURENÇO; CAPELLINI, 2013).

Contudo, o que se observa é que uma criança com diagnóstico comprovado de TEA tem dificuldade para ingressar na rede regular de ensino devido as suas especificidades, com dificuldades na comunicação, na interação e problemas no desenvolvimento de forma geral.

Para a escola também não é tarefa fácil, pois além de buscar as regularizações necessárias ao cumprimento do direito da criança diante das necessidades legais, há a necessidade de trabalhar também a convivência com os colegas para que se evitem os episódios de exclusão.

Também há dificuldade com a preparação dos profissionais que tem de adequar suas práticas às necessidades dos alunos com TEA, o que exige uma atuação baseada na compreensão do que precisa ser trabalhado observando o comportamento da criança e sua relação com os colegas e vise versa.

Faz-se necessário nessas circunstâncias, um professor criativo que proponha atividades que integrem as crianças, reforce as atitudes positivas e possibilitem o desenvolvimento das mesmas.

É indispensável também a integração familiar, pois a família como primeira via social da criança, precisa acompanhar de perto o desenvolvimento da criança, especialmente nos aspectos social e cognitivo.

Discorrendo sobre TEA Khoury (2014) afirma que, como em outros transtornos do desenvolvimento, crianças com TEA possuem necessidades educacionais especiais devido às condições clínicas, comportamentais, cognitivas, de linguagem e de adaptação social que apresentam. Precisam, muitas vezes, de adaptações curriculares e de estratégias de manejo adequadas.

Continua o autor, quando as necessidades educacionais de crianças com TEA são atendidas, respeitando a condição espectral do transtorno, ações educacionais poderão garantir que alcancem o nível universitário, especialmente aquelas que não apresentam deficiência intelectual importante, assim como qualidade de vida individual e familiar e inserção social no mercado de trabalho, sempre que as condições fenotípicas da doença possibilitem.

Nessa linha de pensamento o pesquisador Cunha (2012), afirma também que: 
psicopedagogo para que dê suporte ao professor em sala de aula. $\mathrm{Na}$ escola inclusiva, é demasiadamente difícil para um único educador atender a uma classe inteira com diferentes níveis educacionais e, ainda, propiciar uma educação inclusiva adequada. Tudo o que for construído no ambiente escolar deverá possuir o gene da qualidade (CUNHA, 2012, p. 55).

De fato é perceptível no contexto escolar as dificuldades dos profissionais no dia a dia com crianças com TEA, uma vez que, por mais que o marco legal assegure tal direito, ainda depare-se com situações desafiadoras como falta de profissional capacitado e em muitas das vezes, negação da educação inclusiva caracterizada pelo despreparo para trabalhar com crianças com algum tipo de transtorno.

$\mathrm{Na}$ educação Infantil o percurso da aprendizagem de crianças com TEA perpassa por dificuldades de atenção, raciocínio e de aceitação dos erros presentes em sala de aula. Recusar de maneira sutil ou explícita o ensino a uma criança autista é anular o seu potencial que necessita ser explorado e lapidado, é retirar o direito ao desenvolvimento e encerrar os fluxos e vínculos de comunicação que são tão difíceis de construir no peculiar universo da criança.

Dessa forma, torna-se indispensável à construção de novas práticas pedagógicas, como a formação continuada e treinamento de profissionais com 0 objetivo promover a inclusão de forma mais suave. A escola deve ser percebida pelo aluno com TEA e pela família como um espaço transformador, acolhedor e instigante do aprendizado. Qualificar a escola e seus profissionais no processo da inclusão é um caminho seguro para viabilizar os valores humanitários como o respeito e a igualdade.

\section{Mediação do professor na inclusão de alunos com Transtorno do Espectro Autista}

A aprendizagem se processa pelo desenvolvimento das capacidades e habilidades dos alunos transmitindo valores e práticas culturais que serão utilizados e praticados por toda a vida. Com a constituição/ 1988 a educação tornou-se direito de todas as crianças, com gratuidade e acesso, exercendo a sua cidadania.

A LDB, Lei de Diretrizes e Bases da Educação Nacional, também assegura nos seus artigos 29 e 30, que a educação infantil, a primeira etapa da educação básica, seja oferecida em creches para as crianças de zero a três anos e em préescolas para as crianças de quatro a cinco anos de idade. 
No entanto, a educação como um direito de todos ainda depende políticas públicas que inclua realmente todos os alunos no âmbito escolar, incluindo o aluno com qualquer tipo de deficiência ou transtorno.

A Lei $n^{0}$ 13.005/2014 que instituiu o Plano Nacional de Educação preconiza que a inclusão das pessoas com algum tipo de deficiência seja atendida preferencialmente na educação básica com a garantia de sistema educacional inclusivo, de salas de recursos multi funcionais, classes, escolas ou serviços especializados, públicos ou conveniados. (BRASIL, 2014, p.70).

É fato que os professores devem incluir todos os alunos, mas é certo que encontrarão desafios para inserir o aluno com transtorno espectro autista na sala de aula, em razão de muitos profissionais não terem formação adequada para trabalhar com essa deficiência, como por exemplo, a linguagem do aluno, o nível de compreensão e percepção do aluno, a agressividade da criança, o desconhecimento em relação a novas práticas pedagógicas, a adequação do espaço físico, falta de recursos ou insuficiência e inadequação dos mesmos que possam proporcionar um ensino adequado, motivante e interessante aos alunos com TEA.

Apesar das dificuldades o professor necessita incluir os alunos com TEA proporcionando aos mesmos, oportunidades iguais aos demais, de forma que sejam aceitos e incluídos pelas colegas e pela sociedade com a consciência de que uma criança autista pode e deve desenvolver suas habilidades e aprendizagem indispensável no processo inclusivo.

De acordo com Mantoan (2003):

\begin{abstract}
A escola para ser inclusiva, deve acolher todos os alunos, independente de suas condições sociais, emocionais, físicas, intelectuais, linguísticas, entre outras. Ela deve ter como princípio básico desenvolver uma pedagogia capaz de educar e incluir todos aqueles com necessidades educacionais especiais e também os que apresentam dificuldades temporárias ou permanentes, pois a inclusão não se aplica apenas aos alunos que apresentam algum tipo de deficiência. (MONTOAN, 2003, p. 143).
\end{abstract}

Dessa maneira, Mantoan afirma que a Inclusão é o privilégio de conviver com as diferenças, isto é, quando professores e alunos percebem e entendem as diferenças dos outros, reconhecendo a importância da inclusão.

A inclusão necessita ser praticada no currículo escolar não somente com alunos com alguma deficiência ou com algum transtorno, mas é dever da escola criar um currículo adequado que atenda o aluno com suas dificuldades particulares. 
Para a escola mudar na prática e inserir-se no processo inclusivo, precisa assumir que as diferenças são positivas na aprendizagem de todos introduzindo recursos e práticas capazes de referendar a aprendizagem. É necessário que o professor esteja disposto trabalhar com qualquer dificuldade que surja em sala adequando sua prática às necessidades dos alunos, atualizando-se através de novas leituras, especializando-se com novos conhecimentos.

Enfrentando os desafios que a educação inclusiva propõe, confirma-se que a educação é para todos, é direito de todos e a inclusão pode ser a realidade de muitas escolas, trabalhando com as diferenças existentes. E, a sociedade como um todo deve contribuir para que seja implantada em qualquer ambiente a inclusão buscando sempre novas formas de inserir as crianças, cooperando para um mundo com mais respeito e menos preconceito.

Partindo do contexto que o TEA apresenta níveis de desenvolvimento e ainda grupos verbalizados e não verbalizados, pode-se dizer que o desafio não é pequeno; e além destas características citadas existe a singularidade de cada criança, deixando para os professores uma responsabilidade ainda maior.

Para MELLO, 2007, devido aos diferentes graus do TEA, as intervenções têm que serem adequadas a casa tipo ou grau de comprometimento. Para crianças com TEA, verbalizadas, sem Deficiência intelectual (DI), deve-se desenvolver enquanto antes a autonomia, a independência, a comunicação não verbal simbólica, aspectos sociais como imitação, aprender a esperar a vez, aprender a participar de jogos de equipe para problemas de comportamento e aumentar a socialização, ensinar a flexibilizar tendências repetitivas, desenvolver habilidades cognitivas e acadêmicas, buscando atividades diárias como ajudante do dia do professor, fazer lista de atividades, usarem agendas e calendários para melhor organização, estimular trabalhos em grupo, ensinar a pedir ajuda quando necessário, ser elogiado sempre que for bem sucedido, ser acompanhado no intervalo do recreio para que não fique aéreo e seja alvo de brincadeiras e julgamentos inadequados de outras crianças e também para ser guiado a coisas de seu interesse.

Para ajudar no desenvolvimento cognitivo das crianças com TEA, existem métodos que apesar de eficientes, pouco é divulgado no ambiente escolar. Dar-se-á, aqui, a explanação de alguns deles, não com o intuito de dizer qual o melhor, mas na intenção de apresentar alternativas de trabalho para uma inclusão relevante. 
Conforme UCHÔA, 2015, o método TEACCH (Tratamento e Educação para Autista e Crianças com Déficits Relacionados à comunicação), tem avançado o seu uso no Brasil. Esse método objetiva trabalhar formas de adaptações do ambiente, porém precisa uma análise individual porque mesmo que as crianças apresentem mesmo diagnóstico suas necessidades e suas dificuldades são diferentes.

Esse método TEACCH foi desenvolvido no Departamento de Psiquiatria da Faculdade de Medicina da Universidade da Carolina do Norte, Estados Unidos, nos anos 60, foi idealizado e desenvolvido pelo Dr. Eric Schoppler, e atualmente tem como responsável o Dr. Gary Mesibov.

\begin{abstract}
O método TEACCH utiliza uma avaliação chamada PEP-R (Perfil Psicoeducacional Revisado) para avaliar a criança, levando em conta os seus pontos fortes e suas maiores dificuldades, tornando possível um programa individualizado. O TEACCH se baseia na organização do ambiente físico através de rotinas - organizadas em quadros, painéis ou agendas - e sistemas de trabalho, de forma a adaptar o ambiente para tornar mais fácil para a criança compreendê-lo, assim como compreender o que se espera dela. Através da organização do ambiente e das tarefas da criança, o TEACCH visa desenvolver a independência da criança de modo que ela necessite do professor para o aprendizado, mas que possa também passar grande parte de seu tempo ocupando-se de forma independente. (MELLO, 2007)
\end{abstract}

Segundo UCHÔA, 2015, O TEACCH também auxilia a família, pois elas devem organizar o ambiente da casa, dando mais segurança à criança e ao mudar o ambiente deverá avisar com antecedência, para que não se frustre com a mudança do ambiente e vá se acostumando com o novo ambiente ao qual irá.

BOSSA, 2006, aponta que métodos em que usam sinais têm sido amplamente utilizados. Tem-se o MAKATON que utiliza símbolos e sinais. É um método muito utilizado no Reino Unido. O PECS (Sistema de Comunicação por Troca de Figuras) é um método onde a criança utiliza o Velcro ou adesivos para indicar o início, as alterações ou final das atividades, facilitando a comunicação e a compreensão estabelecendo uma associação entre símbolo e atividade. A Técnica Comunicação Facilitada é outra maneira de trabalhar com autistas usando apoio físico para mãos, braços ou pulsos com o objetivo de incentivar as crianças a utilizarem cartões de comunicação de vários tipos proporcionando melhoras nas habilidades de comunicação e linguagem.

MELLO, 2007, apresenta a ABA (Análise Aplicada do Comportamento) como um método: 
visa ensinar à criança habilidades que ela não possui, através da introdução destas habilidades por etapas. Cada habilidade é ensinada, em geral, em esquema individual, inicialmente apresentando-a associada a uma indicação ou instrução. Quando necessário, é oferecido algum apoio (como por exemplo, apoio físico), que deverá ser retirado tão logo seja possível, para não tornar a criança dependente dele. A resposta adequada da criança tem como consequência a ocorrência de algo agradável para ela, o que na prática é uma recompensa. Quando a recompensa é utilizada de forma consistente, a criança tende a repetir a mesma resposta.O primeiro ponto importante é tornar o aprendizado agradável para a criança. $O$ segundo ponto é ensinar a criança a identificar os diferentes estímulos. Respostas problemáticas, como negativas ou birras, não são, propositalmente, reforçadas. A criança é levada a trabalhar de forma positiva, para que não ocorram os comportamentos indesejados.

Todos os métodos e técnicas descritas acima têm sido usadas, a grande maioria, há dezenas de anos não como resultados milagrosos mas sim como formas que podem colaborar com o desenvolvimento dessas crianças, se aplicadas de modo consciente, com adaptações a cada criança, observando seu estilo e cultura. Um número grande de países vem combinando essas técnicas e métodos entre si para buscar o melhor desenvolvimento possível e reabilitação de crianças com TEA, tendo maiores resultados aquelas que começam cedo à intervenção, por isso a necessidade de um diagnóstico precoce e também o envolvimento dos pais na construção de uma atitude de trabalho positiva.

\section{Considerações finais}

Foi possível constatar mediante a pesquisa que o Brasil possui uma avançada legislação sobre educação inclusiva, e em especial inclusão dos autistas com a Lei Berenice Piana, Lei oㅜ 12.754/2012, que referenda ainda mais os dispositivos legais com expressivos avanços tanto na ordem pedagógica como o direito ao acompanhante especializado em caso de comprovada necessidade, como a intersetorialidade de ações políticas no atendimento à pessoa com Transtorno do Espectro Autista, (TEA).

Não há menor dúvida que os alunos com TEA possuem uma forma peculiar de aprender e que, portanto, se faz necessárias adaptações no ambiente escolar que proporcionem progressos tanto no aspecto educacional como social.

O trabalho proposto expôs as inquietações acerca do TEA, assim como motivar reflexões com proposta de releitura no ambiente escolar garantindo ao aluno com TEA um aprendizado significativo. Se a proposta é efetivar a educação inclusiva com atendimento ao TEA integrando e o inserindo-o no espaço escolar, não há 
como não adaptar esse espaço num ambiente apropriado para fomentar o processo de aprendizagem desse aluno.

Assim, pode-se relatar que inclusão não é apenas colocar o aluno dentro do contexto escolar, mas adaptar esse contexto à realidade do aluno possibilitando-o construir novos conhecimentos de maneira própria e no seu tempo. A aprendizagem da criança com TEA deve ser sempre acompanhada pelo professor, proporcionando a ambos se relacionarem e enriquecerem os conhecimentos com aplicação de novas estratégias de intervenção que estimulem a aprendizagem do aluno com TEA.

Diante do exposto, é imprescindível que o profissional busque enriquecer sua prática capacitando-se constantemente, pois a formação continuada enriquece não só sua prática, mas também na vida de forma geral.

Conclui-se dizendo que é preciso repensar o processo inclusivo das escolas de modo geral, mas especialmente as de Educação Infantil, para que amem suas crianças acima de suas diferenças e necessidades e que as encorajem a permanecer, desenvolver e aprender.

Pois como cita Rubem Alves, 2004:

Escolas que são gaiolas existem para que pássaros desaprendam a
arte do voo. Pássaros engaiolados são pássaros sob controle.
Engaiolados, o seu dono pode levá-los para onde quiser. Pássaros
engaiolados tem sempre um dono. Deixaram de ser pássaros. Porque
a essência dos pássaros é o voo. Escolas que são asas não amam
pássaros engaiolados. O que elas amam são os pássaros em voo.
Existem para dar aos pássaros coragem para voar. Ensinar o voo,
isso elas não podem fazer, porque o voo já nasce dentro dos
pássaros. O voo não pode ser ensinado, apenas encorajado.
(RUBEM ALVES, 2004, p.27)

E as escolas, especialmente da educação infantil, jamais podem ser gaiolas, mas sim escolas asas que permitam aos seus alunos alçarem longos voos em busca do conhecimento e da aprendizagem possível de forma instigante e prazerosa.

\section{Referências}

Lei Federal $\mathrm{n}^{0}$ 12.764/2012, de 27 de dezembro de 2012. Institui a Política Nacional de Proteção dos Direitos da Pessoa com Transtorno do Espectro Autista; e altera o § 30 do art. 98 da Lei no 8.112, de 11 de dezembro de 1990. Diário Oficial [da] República Federativa do Brasil, Brasília, DF: 28 dez. 2012.

. Decreto Federal no 8.368/2014, de 02 de dezembro de 2014. Regulamenta a Lei no 12.764, de 27 de dezembro de 2012, que institui a Política 
Nacional de Proteção dos Direitos da Pessoa com Transtorno do Espectro Autista. Diário Oficial [da] República Federativa do Brasil, Brasília, DF: 2014.

. Lei no 9.394, de 20 de dezembro de 1996. Estabelece as diretrizes e bases da educação nacional. Diário Oficial da União, Brasília, DF, 1996.

. Lei no 13.005, de 25 de junho de 2014. Aprova o Plano Nacional de Educação - PNE e dá outras providências. Diário Oficial da União, Brasília, DF, 26 jun. 2014.

ALVES, R. Gaiolas ou asas: a arte do voo ou a busca da alegria de aprender. Porto: Edições Asa, 2004.

BOSA, Cleonice A. Autismo: intervenções psicoeducacionais. Revista brasileira de psiquiatria - Brazilianjournalofpsychiatry. 2006.

BOTTGER, A.R.S.; LOURENÇO, A.C.; CAPELLINI, V.L.M.F. O professor da Educação Especial e o processo de ensino-aprendizagem de alunos com autismo. Revista de Educação Especial, v.26, n.46, 2013.

BRASIL. Constituição (1998). Constituição da República Federativa do Brasil. Brasília, DF: Senado, 5 out. 1998.

CUNHA, Eugênio. Autismo e inclusão: psicopedagogia e práticas educativas na escola e na família. 4. ed. Rio de Janeiro: Wak Editora, 2012.

KHOURY, Laís Pereira, TEIXEIRA, Maria Cristina Triguero Veloz, CARREIRO, Luiz Renato Rodrigues, SCHWARTZMAN José Salomão, RIBEIRO, Adriana de Fátima, CANTIERI, Carla Nunes. Manejo comportamental de crianças com Transtornos do Espectro do Autismo em condição de inclusão escolar: guia de orientação a professores [livro eletrônico]. São Paulo: Memnon, 2014.

MANTOAN, M.T. Inclusão social: o que é? Por quê? Como fazer? São Paulo: Moderna, 2003.

MELLO, Ana Maria S. Ros de. Autismo: guia prático. 7.ed.Colaboração: Marialice de Castro Vatavuk.6.ed.São Paulo: AMA; Brasília: CORDE, 2007, 104 p.

OLIVEIRA, Karina G, SERTIÉ, Andréa L. Transtornos do espectro autista: um guia atualizado para aconselhamento genético. Einstein. 2017;

SILVA, Dulcilene R; TAVARES, Daniel M. Educação Infantil: avanços e desafios, onde $o$ discurso e a prática se encontram.

SOUZA, Marjane B. SILVA Priscila D.L. Equoterapia no tratamento do transtorno do espectro autista: a percepção dos técnicos. 2015.

UCHÔA, Yasmim Figueiredo. A Criança autista na educação infantil: desafios e possibilidades na educação inclusiva. 21 ed. CDD371.94. 2015. 40p. 
ZANON, Regina B; BACKES Barbara; BOSA, Cleonice A. Identificação dos primeiros sintomas do autismo pelos pais. Psicologia: teoria e pesquisa. v. 30 , n.1, p. 25-33, 2014. 